\title{
A Heuristic Knowledge Reduction Algorithm Based on Partition Subdivision and Consistent Degree
}

\author{
Wen Huo and Xiaoguang Hong
}

College of Computer Science and Technology,Shandong University, hw112200@hotmail.com

\begin{abstract}
In this paper, a new knowledge reduction definition based on partition subdivision is proposed, its equivalence to the classic attribute reduction definition based on positive region is proved, and a consistent degree is introduced to evaluate the importance of condition attribute for decision attribute. Based on the above results, a heuristic knowledge reduction algorithm is designed.
\end{abstract}

Keywords: data mining, knowledge reduction, rough set, decision table, positive region, partition subdivision, consistent degree

\section{Introduction}

Knowledge reduction is one of the key problems of knowledge discovery in data mining. There are two classical definitions of knowledge reduction in rough set theory: one is based on positive region, the other is based on condition information entropy, but they are not equivalent when they deal with inconsistent decision table. In 2005 a definition based on the new condition information entropy was proposed $^{[1]}$, and its equivalence to the definition based on positive region was explained by a knowledge reduction algorithm. In 2006 a definition based on the average decision power was proposed ${ }^{[2]}$. Afterwards, the average decision power was amended to the decision power ${ }^{[3]}$ in 2007 , but the definition based on the decision power is not equivalent to the classical definition based on positive region.

Being illuminated by all the above research, this paper proposed a new knowledge reduction definition based on partition subdivision, and its equivalence to the classical definition based on positive region is proved. Furthermore, a consistent degree is introduced to evaluate the importance of condition attribute for decision attribute. Based on the above results, a heuristic knowledge reduction algorithm based on partition subdivision and consistent degree is designed. 


\section{Basic Notations and Definitions}

[Definition 1] ${ }^{[4,5]}$ The notion of information system is formally defined as $\mathrm{S}=(\mathrm{U}, \mathrm{A}, \mathrm{V}, \mathrm{f})$, and $\mathrm{U}, \mathrm{A}, \mathrm{V}, \mathrm{f}$ is defined as follows: $\mathrm{U}$ : nonempty set of objects, called universe; A: nonempty set of attributes; $\mathrm{V}=\mathrm{Y}, \mathrm{Va}, \mathrm{Va}$ is the range of attribute $\mathrm{a} ; \mathrm{f}: \mathrm{U} \times \mathrm{A} \rightarrow \mathrm{V}$ is an information function, $\forall \mathrm{x} \in \mathrm{U}, \mathrm{a} \in \mathrm{A}, \mathrm{f}(\mathrm{x}, \mathrm{a}) \in \mathrm{Va}$.

$\forall \mathrm{P} \subseteq \mathrm{A}, \mathrm{IND}(\mathrm{P})=\{(\mathrm{x}, \mathrm{y}) \mid(\mathrm{x}, \mathrm{y}) \in \mathrm{U} \times \mathrm{U}$ and $\forall \mathrm{a} \in \mathrm{P}, \mathrm{f}(\mathrm{x}, \mathrm{a})=\mathrm{f}(\mathrm{y}, \mathrm{a})\}$ is an equivalence relation on $\mathrm{U}$, so $\mathrm{U} / \mathrm{IND}(\mathrm{P})$, shortly written as $\mathrm{U} / \mathrm{P}$, forms an partition on $\mathrm{U}$.

If attribute set $\mathrm{A}$ can be divided into condition attribute set $\mathrm{C}$ and decision attribute set $\mathrm{D}$, namely, $\mathrm{C} \cup \mathrm{D}=\mathrm{A}, \mathrm{C} \cap \mathrm{D}=\varnothing$, then $\mathrm{S}$ is termed decision table, shortly written as $\mathrm{S}=(\mathrm{U}, \mathrm{C}, \mathrm{D})$.

[Definition 2] ${ }^{[4,5]}$ In decision table $\mathrm{T}=(\mathrm{U}, \mathrm{C}, \mathrm{D}), \quad \mathrm{P} \subseteq \mathrm{C} \cup \mathrm{D}, \quad \forall \mathrm{X} \subseteq \mathrm{U}$, $\underline{\mathrm{PX}}=\cup\{\mathrm{Y} \mid \mathrm{Y} \in \mathrm{U} / \mathrm{P}$ and $\mathrm{Y} \subseteq \mathrm{X}\}$ is termed the lower approximation of $\mathrm{X}$. $\operatorname{POS}_{\mathrm{P}}(\mathrm{D})$ $=\underset{X \in U / D}{\mathrm{Y}} \underline{\mathrm{PX}}$ is termed the $\mathrm{P}$ positive region of $\mathrm{D}$.

\section{The Classical Knowledge Reduction Definition Based on Positive Region}

$\left[\right.$ Definition 3] ${ }^{[4,5]}$ In decision table $\mathrm{T}=(\mathrm{U}, \mathrm{C}, \mathrm{D}), \mathrm{A} \subseteq \mathrm{C}$, if $\operatorname{POS}_{\mathrm{A}}(\mathrm{D})=\mathrm{POS}_{\mathrm{C}}(\mathrm{D})$, and $\forall \mathrm{a} \in \mathrm{A}, \operatorname{POS}_{\mathrm{A}^{-}\{\mathrm{a}\}} \neq \mathrm{POS}_{\mathrm{C}}(\mathrm{D})$, then $\mathrm{A}$ is termed a knowledge reduction of $\mathrm{C}$ with respect to $D$.

\section{The Knowledge Reduction Definition Based on Partition Subdivision}

[Definition 4] $]^{[1]}$ In decision table $\mathrm{T}=(\mathrm{U}, \mathrm{C}, \mathrm{D}), \mathrm{U} / \mathrm{D}=\left\{\mathrm{Y}_{1}, \mathrm{Y}_{2}, \ldots, \mathrm{Y}_{\mathrm{m}}\right\}, \mathrm{A} \subseteq \mathrm{C}$, let $\mathrm{Y}_{0}=\mathrm{U}-\mathrm{POS}_{\mathrm{A}}(\mathrm{D})$, then the set cluster $\mathrm{R}_{\mathrm{A}}=\left\{\underline{\mathrm{A}} \mathrm{Y}_{0}, \underline{\mathrm{A}} \mathrm{Y}_{1}, \underline{\mathrm{A}} \mathrm{Y}_{2}, \ldots, \underline{\mathrm{A}} \mathrm{Y}_{\mathrm{m}}\right\}$ is termed a partition on $\mathrm{U}$ educed by $\mathrm{A}$.

Definition 4 is explained as follows: $\underline{A} Y_{0}=Y_{0}=U-P_{A}(D)$ can be proved easily, and ${\underset{\mathrm{Y}}{\mathrm{Y}=1}}^{m} \underline{\mathrm{A}} \mathrm{Y}_{\mathrm{i}}=\operatorname{POS}_{\mathrm{A}}(\mathrm{D})$, if $\varnothing$ exists in $\mathrm{R}_{\mathrm{A}}$, then $\mathrm{R}_{\mathrm{A}}$ is still a partition on $\mathrm{U}$ after delete the $\varnothing$, so we can suppose there is no $\varnothing$ in $\mathrm{R}_{\mathrm{A}}$.

[Definition 5] $\mathrm{U} / \mathrm{P}=\left\{\mathrm{P}_{1}, \quad \mathrm{P}_{2}, \ldots, \quad \mathrm{P}_{\mathrm{m}}\right\}, \mathrm{U} / \mathrm{Q}=\left\{\mathrm{Q}_{1}, \quad \mathrm{Q}_{2}, \ldots, \quad \mathrm{Q}_{\mathrm{n}}\right\}$, if $\forall \mathrm{Q}_{\mathrm{i}} \in \mathrm{U} / \mathrm{Q}, \exists \mathrm{P}_{\mathrm{k}} \in \mathrm{U} / \mathrm{P}, \mathrm{Q}_{\mathrm{i}} \subseteq \mathrm{P}_{\mathrm{k}}$, then we say $\mathrm{U} / \mathrm{Q}$ is a partition subdivision of $\mathrm{U} / \mathrm{P}$. 
Based on Definition 4 and Definition 5, we propose a new knowledge reduction definition based on partition subdivision as follows:

[Definition 6] In decision table $\mathrm{T}=(\mathrm{U}, \mathrm{C}, \mathrm{D}), \mathrm{U} / \mathrm{D}=\left\{\mathrm{Y}_{1}, \mathrm{Y}_{2}, \ldots, \mathrm{Y}_{\mathrm{m}}\right\}, \mathrm{R}_{\mathrm{C}}=$

$\left\{\underline{C Y}_{0}, \underline{\mathrm{CY}_{1}}, \underline{\mathrm{C}} \mathrm{Y}_{2}, \ldots, \underline{\mathrm{C}} \mathrm{Y}_{\mathrm{m}}\right\}, \mathrm{A} \subseteq \mathrm{C}$, if $\mathrm{U} / \mathrm{A}$ is a partition subdivision of $\mathrm{R}_{\mathrm{C}}$, and $\forall \mathrm{a} \in \mathrm{A}, \mathrm{U} /(\mathrm{A}-\{\mathrm{a}\})$ is not the partition subdivision of $\mathrm{R}_{\mathrm{C}}$, then $\mathrm{A}$ is termed a knowledge reduction of $\mathrm{C}$ with respect to $\mathrm{D}$.

\section{The Equivalence between Definition 6 and Definition 3}

[Lemma 1] ${ }^{[1]}$ In decision table $\mathrm{T}=(\mathrm{U}, \mathrm{C}, \mathrm{D}), \mathrm{U} / \mathrm{D}=\left\{\mathrm{Y}_{1}, \mathrm{Y}_{2}, \ldots, \mathrm{Y}_{\mathrm{m}}\right\}, \mathrm{A} \subseteq \mathrm{C}$, then $\mathrm{POS}_{\mathrm{A}}(\mathrm{D})=\mathrm{POS}_{\mathrm{C}}(\mathrm{D}) \Leftrightarrow \underline{\mathrm{A}} \mathrm{Y}_{\mathrm{i}}=\underline{\mathrm{C}} \mathrm{Y}_{\mathrm{i}}, \forall \mathrm{i} \in\{0,1,2, \ldots, \mathrm{m}\}$.

[Lemma 2] In decision table $\mathrm{T}=(\mathrm{U}, \mathrm{C}, \mathrm{D}), \mathrm{A} \subseteq \mathrm{C}, \mathrm{R}_{\mathrm{A}}=\left\{\underline{\mathrm{A}} \mathrm{Y}_{0}, \underline{\mathrm{A}} \mathrm{Y}_{1}, \underline{\mathrm{A}} \mathrm{Y}_{2}, \ldots\right.$, $\left.\underline{\mathrm{A}} \mathrm{Y}_{\mathrm{m}}\right\}$, then $\mathrm{U} / \mathrm{A}$ is a partition subdivision of $\mathrm{R}_{\mathrm{A}}$.

Proof: Suppose $U / A=\{A 1, A 2, \ldots, A n\}, U / D=\left\{Y_{1}, Y_{2}, \ldots, Y_{m}\right\}$, because of $\underline{A} Y_{j}=\cup\left\{A_{i} \mid A_{i} \subseteq Y_{j}\right\}, j=1,2 \ldots, m$, some partition blocks should be a subdivision of $\left\{\underline{A Y}_{0}, \underline{A Y}_{1}, \underline{A Y}_{2}, \ldots, \underline{A} Y_{m}\right\}$, and the other partition blocks should be a subdivision of $\underline{A} Y_{0}=U-P_{A}(D)$, so $U / A$ is a subdivision of $R_{A}$.

[Theorem 1] In decision table $\mathrm{T}=(\mathrm{U}, \mathrm{C}, \mathrm{D}), \mathrm{U} / \mathrm{D}=\left\{\mathrm{Y}_{1}, \mathrm{Y}_{2}, \ldots, \mathrm{Y}_{\mathrm{m}}\right\}, \mathrm{A} \subseteq \mathrm{C}$, $\mathrm{R}_{\mathrm{C}}=\left\{\underline{\mathrm{CY}}_{0}, \underline{\mathrm{CY}}_{1}, \underline{\mathrm{C}} \mathrm{Y}_{2}, \ldots, \underline{\mathrm{C}} \mathrm{Y}_{\mathrm{m}}\right\}$, then $\operatorname{POS}_{\mathrm{A}}(\mathrm{D})=\mathrm{POS}_{\mathrm{C}}(\mathrm{D}) \Leftrightarrow \mathrm{U} / \mathrm{A}$ is a partition subdivision of $\mathrm{R}_{\mathrm{C}}$.

Proof: 1) First, we prove " $\Rightarrow$ ": If $\operatorname{POS}_{\mathrm{A}}(\mathrm{D})=\mathrm{POS}_{\mathrm{C}}(\mathrm{D})$, then according to Lemma 1 we can get $\underline{\mathrm{A}} \mathrm{Y}_{\mathrm{i}}=\underline{\mathrm{C}} \mathrm{Y}_{\mathrm{i}}, \forall \mathrm{i} \in\{0,1,2, \ldots, \mathrm{m}\}$, namely, $\mathrm{R}_{\mathrm{A}}=\mathrm{R}_{\mathrm{C}}$. Moreover, $\mathrm{U} / \mathrm{A}$ is a partition subdivision of $\mathrm{R}_{\mathrm{A}}$ according to Lemma 2, so U/A is a partition subdivision of $\mathrm{R}_{\mathrm{C}}$ too.

2) Second, we prove " $\Leftarrow$ ": If U/A is a partition subdivision of $R_{C}$, let $\mathrm{U} / \mathrm{A}=\left\{\mathrm{A}_{1}, \mathrm{~A}_{2}, \ldots, \mathrm{A}_{\mathrm{n}}\right\}$, and

$\underset{i=1}{k_{1}} \mathrm{~A}_{\mathrm{i}}=\underline{\mathrm{CY}}_{0}, \underset{i=k_{1}+1}{k_{2}} \mathrm{~A}_{\mathrm{i}}=\underline{\mathrm{C}} \mathrm{Y}_{1}, \ldots, \underset{i=k_{m}+1}{\mathrm{Y}} \mathrm{A}_{\mathrm{i}}=\underline{\mathrm{C}} \mathrm{Y}_{\mathrm{m}} .\left(^{*}\right)$ Then we can get the following conclusions:

Conclusion 1: $\forall \mathrm{i} \in\left\{\mathrm{k}_{1}+1, \mathrm{k}_{1}+2, \ldots, \mathrm{n}\right\}, \exists \mathrm{j} \in\{1,2, \ldots, \mathrm{m}\}, \mathrm{A}_{\mathrm{i}} \subseteq \mathrm{Y}_{\mathrm{j}}$.

Conclusion 2: $\forall \mathrm{i} \in\left\{1,2, \ldots, \mathrm{k}_{1}\right\}, \forall \mathrm{j} \in\{1,2, \ldots, \mathrm{m}\}, \mathrm{A}_{\mathrm{i}} \not \subset \mathrm{Y}_{\mathrm{j}}$.

Proof of Conclusion 1: For $\forall \mathrm{i} \in\left\{\mathrm{k}_{1}+1, \mathrm{k}_{1}+2, \ldots, \mathrm{n}\right\}$, according to $\left(^{*}\right)$ we can get that $\exists \mathrm{j} \in\{1,2, \ldots, \mathrm{m}\}, \mathrm{A}_{\mathrm{i}} \subseteq \underline{\mathrm{C}} \mathrm{Y}_{\mathrm{j}}$, because of $\underline{\mathrm{C}} \mathrm{Y}_{\mathrm{j}} \subseteq \mathrm{Y}_{\mathrm{j}}$, so $\mathrm{A}_{\mathrm{i}} \subseteq \mathrm{Y}_{\mathrm{j}}$.

Proof of Conclusion 2: Suppose $\mathrm{U} / \mathrm{C}=\left\{\mathrm{C}_{1}, \mathrm{C}_{2}, \ldots, \mathrm{Cs}\right\}, \quad \underline{\mathrm{C}} \mathrm{Y}_{0}={\underset{\mathrm{Y}}{\mathrm{Y}} \mathrm{q}}_{\mathrm{k}}, \mathrm{q} \leq \mathrm{s}$, and $\forall \mathrm{k} \in\{1,2, \ldots, \mathrm{q}\}, \forall \mathrm{j} \in\{1,2, \ldots, \mathrm{m}\}, \mathrm{C}_{\mathrm{k}} \not \subset \mathrm{Y}_{\mathrm{j}}(* *)$, thus $\underset{i=1}{\mathrm{~K}_{1}} \mathrm{~A}_{\mathrm{i}}=\underset{k=1}{\mathrm{q}} \mathrm{C}_{\mathrm{k}}$. Because of $\mathrm{U} / \mathrm{C}$ is a partition subdivision of $\mathrm{U} / \mathrm{A}^{[7]},\left\{\mathrm{C}_{1}, \mathrm{C}_{2}, \ldots, \mathrm{C}_{\mathrm{q}}\right\}$ is definitely a partition 
subdivision of $\left\{\mathrm{A}_{1}, \mathrm{~A}_{2}, \ldots, \mathrm{A}_{\mathrm{k} 1}\right\}$, so $\forall \mathrm{i} \in\left\{1,2, \ldots, \mathrm{k}_{1}\right\}, \mathrm{A}_{\mathrm{i}}$ is the union of some $\mathrm{C}_{\mathrm{k}}(\mathrm{k} \in\{1,2, \ldots, \mathrm{q}\})$, then we can get that $\forall \mathrm{j} \in\{1,2, \ldots, \mathrm{m}\}, \mathrm{A}_{\mathrm{i}} \not \subset \mathrm{Y}_{\mathrm{j}}$ due to (**), otherwise, suppose that $\exists \mathrm{j} \in\{1,2, \ldots, \mathrm{m}\}, \mathrm{A}_{\mathrm{i}} \subseteq \mathrm{Y}_{\mathrm{j}}$, thus $\mathrm{C}_{\mathrm{k}} \subseteq \mathrm{Y}_{\mathrm{j}}$, which is inconsistent with $(* *)$.

According to Conclusion 1, Conclusion 2 and the definition of $A$ positive region of $D$, we can get that

$$
\mathrm{U}-\operatorname{POS}_{\mathrm{A}}(\mathrm{D})=\mathrm{Y}_{i=1}^{k_{1}} \mathrm{~A}_{\mathrm{i}}=\underline{\mathrm{CY}}_{0}=\mathrm{U}-\operatorname{POS}_{\mathrm{C}}(\mathrm{D}) \text {, namely, } \operatorname{POS}_{\mathrm{A}}(\mathrm{D})=\operatorname{POS}_{\mathrm{C}}(\mathrm{D}) \text {. }
$$

From Theorem 1 we can easily get the conclusion that Definition 6 is equivalent to Definition 3.

Now we validate it by the following examples ${ }^{[2]}$ :

Table 1. Decision Table1.

Table 2. Decision Table2.

Table 3. Decision Table3.

\begin{tabular}{lllllllllllllll}
\hline $\mathrm{U}$ & $\mathrm{a}$ & $\mathrm{b}$ & $\mathrm{c}$ & $\mathrm{d}$ & $\mathrm{U}$ & $\mathrm{a}$ & $\mathrm{b}$ & $\mathrm{c}$ & $\mathrm{d}$ & $\mathrm{U}$ & $\mathrm{a}$ & $\mathrm{b}$ & $\mathrm{c}$ & $\mathrm{d}$ \\
1 & 1 & 0 & 0 & 1 & 1 & 1 & 1 & 0 & 1 & 1 & 1 & 1 & 0 & 1 \\
2 & 2 & 1 & 1 & 3 & 2 & 3 & 1 & 2 & 0 & 2 & 3 & 1 & 2 & 0 \\
3 & 3 & 1 & 2 & 0 & 3 & 3 & 1 & 2 & 0 & 3 & 3 & 1 & 2 & 0 \\
4 & 3 & 1 & 2 & 0 & 4 & 3 & 1 & 2 & 0 & 4 & 3 & 1 & 2 & 0 \\
5 & 3 & 1 & 2 & 1 & 5 & 3 & 1 & 2 & 0 & 5 & 3 & 1 & 2 & 0 \\
6 & 3 & 1 & 2 & 1 & 6 & 3 & 1 & 2 & 1 & 6 & 3 & 1 & 2 & 3 \\
7 & 3 & 1 & 1 & 0 & 7 & 3 & 3 & 0 & 0 & 7 & 3 & 3 & 0 & 2 \\
8 & 3 & 1 & 1 & 0 & 8 & 3 & 3 & 0 & 0 & 8 & 3 & 3 & 0 & 2 \\
9 & 3 & 1 & 1 & 1 & 9 & 3 & 3 & 0 & 0 & 9 & 3 & 3 & 0 & 3 \\
10 & 3 & 1 & 1 & 1 & 10 & 3 & 3 & 0 & 1 & 10 & 3 & 3 & 0 & 3 \\
\hline
\end{tabular}

Table 1, Table 2and Table 3 are all inconsistent decision table, we reduce the condition attribute set by Definition 3 and Definition 6 , the reductive results list in the following table:

Table 4. Reductive Results of Table 1, Table 2 and Table 3.

\begin{tabular}{|l|l|l|l|}
\hline & Table 1 & Table 2 & Table 3 \\
\hline Definition 3 & $\{\mathrm{a}\}$ & $\{\mathrm{a}\},\{\mathrm{b}, \mathrm{c}\}$ & $\{\mathrm{a}\},\{\mathrm{b}, \mathrm{c}\}$ \\
\hline Definition 6 & $\{\mathrm{a}\}$ & $\{\mathrm{a}\},\{\mathrm{b}, \mathrm{c}\}$ & $\{\mathrm{a}\},\{\mathrm{b}, \mathrm{c}\}$ \\
\hline
\end{tabular}

If we restrict to get the minimal reduction, which contains attributes the least, then $\{b, c\}$ should be removed. 


\section{The Consistent Degree of Condition Attribute Subset Relative to $\mathbf{R}_{\mathbf{C}}$}

From Theorem 1 and Definition 6 we can get that if condition attribute subset $\mathrm{A}$ and $\mathrm{B}$ are not reduction, then they are not the partition subdivision of $\mathrm{R}_{\mathrm{C}}$, now, how can we decide which one between $\mathrm{A}$ and $\mathrm{B}$ is more important for decision attribute? Therefore, we introduce the following definition to evaluate the importance of condition attribute subset for decision attribute.

[Definition 7]In decision table $\mathrm{T}=(\mathrm{U}, \mathrm{C}, \mathrm{D}), \mathrm{A} \subseteq \mathrm{C}, \mathrm{U} / \mathrm{D}=\left\{\mathrm{Y}_{1}, \mathrm{Y}_{2}, \ldots, \mathrm{Y}_{\mathrm{m}}\right\}$, $\mathrm{U} / \mathrm{A}=\left\{\mathrm{A}_{1}, \mathrm{~A}_{2}, \ldots, \mathrm{A}_{\mathrm{n}}\right\}, \mathrm{Y}_{0}=\mathrm{U}-\mathrm{POS}_{\mathrm{C}}(\mathrm{D}), \mathrm{R}_{\mathrm{C}}=\left\{\underline{\mathrm{CY}}_{0}, \underline{\mathrm{CY}}{ }_{1}, \underline{\mathrm{CY}} \mathrm{Y}_{2}, \ldots, \underline{\mathrm{C}} \mathrm{Y}_{\mathrm{m}}\right\}$, then

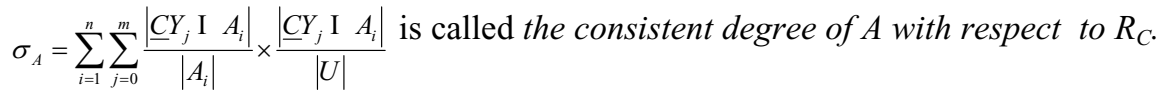
(It is obvious that $0<\sigma_{A} \leq 1$.)

Before we clarify the significance of consistent degree, we firstly prove that $\sigma_{A}=1 \Leftrightarrow \mathrm{U} / \mathrm{A}$ is a partition subdivision of $\mathrm{R}_{\mathrm{C}}$.

[Lemma 3] let $\mathrm{U} / \mathrm{P}=\left\{\mathrm{P}_{1}, \mathrm{P}_{2}, \ldots, \mathrm{P}_{\mathrm{m}}\right\}, \mathrm{U} / \mathrm{Q}=\left\{\mathrm{Q}_{1}, \mathrm{Q}_{2}, \ldots, \mathrm{Q}_{\mathrm{n}}\right\}$, then $\sum_{i=1}^{n} \sum_{j=1}^{m} \frac{\left|P_{j} \mathrm{I} Q_{i}\right|}{\left|Q_{i}\right|} \times \frac{\left|P_{j} \mathrm{I} Q_{i}\right|}{|U|}=1 \Leftrightarrow \mathrm{U} / \mathrm{Q}$ is a partition subdivision of $\mathrm{U} / \mathrm{P}$.

Proof: 1) First, we prove " $\Leftarrow$ ": If $U / Q$ is a partition subdivision of U/P, then $\forall Q_{i} \in U / Q, \exists P_{k} \in U / P, Q_{i} \subseteq P_{k}$, thus $P_{k} \mathrm{I} Q_{i}=Q_{i}$, and for the other $P_{j} \in U / P$, $j \neq k, P_{j}$ I $Q_{i}=\varnothing$.So $\sum_{i=1}^{n} \sum_{j=1}^{m} \frac{\left|P_{j} \mathrm{I} Q_{i}\right|}{\left|Q_{i}\right|} \times \frac{\left|P_{j} \mathrm{I} Q_{i}\right|}{|U|}=\sum_{i=1}^{n}\left(\frac{\left|P_{k} \mathrm{I} Q_{i}\right|}{\left|Q_{i}\right|} \times \frac{\left|P_{k} \mathrm{I} Q_{i}\right|}{|U|}+\sum_{j \neq k} \frac{\left|P_{j} \mathrm{I} Q_{i}\right|}{\left|Q_{i}\right|} \times \frac{\left|P_{j} \mathrm{I} Q_{i}\right|}{|U|}\right)=\sum_{i=1}^{n}\left(\frac{\left|Q_{i}\right|}{|U|}+0\right)=1$

2) Second, we prove " $\Rightarrow$ ": If $U / Q$ is a partition subdivision of $U / P$, then $\exists Q_{s} \in U / Q$, that the elements of $Q_{s}$ come from different $P_{j}$, suppose that there are $x_{1}$ elements come from $P_{j 1}, x_{2}$ elements come from $P_{j 2}, \ldots, x_{k}$ elements come from $P_{j k}, x_{1}+x_{2}+\ldots+x_{k}=\left|Q_{s}\right|$, thus $\sum_{j=1}^{m} \frac{\left|P_{j} \mathrm{I} Q_{s}\right|}{\left|Q_{s}\right|} \times \frac{\left|P_{j} \mathrm{I} Q_{s}\right|}{|U|}=\frac{x_{1}^{2}+x_{2}^{2}+\ldots+x_{k}^{2}}{\left|Q_{s}\right| \times|U|}$, because of $x_{1}, x_{2}, \ldots, x_{k}>0$, it is obvious that $x_{1}^{2}+x_{2}^{2}+\ldots+x_{k}^{2}<\left(x_{1}+x_{2}+\ldots+x_{k}\right)^{2}=\left|Q_{s}\right|^{2}$, thus $\sum_{j=1}^{m} \frac{\left|P_{j} \mathrm{I} Q_{s}\right|}{\left|Q_{s}\right|} \times \frac{\left|P_{j} \mathrm{I} Q_{s}\right|}{|U|}<\frac{\left|Q_{s}\right|^{2}}{\left|Q_{s}\right| \times|U|}=\frac{\left|Q_{s}\right|}{|U|}$.Moreover, $\forall Q_{i} \in U / Q,\left|P_{j} \mathrm{I} \quad Q_{i}\right| \leq\left|Q_{i}\right|$, thus $\sum_{j=1}^{m} \frac{\left|P_{j} \mathrm{I} Q_{i}\right|}{\left|Q_{i}\right|} \times \frac{\left|P_{j} \mathrm{I} Q_{i}\right|}{|U|} \leq \frac{\left|Q_{i}\right|}{|U|}$. So $\sum_{i=1}^{n} \sum_{j=1}^{m} \frac{\left|P_{j} \mathrm{I} Q_{i}\right|}{\left|Q_{i}\right|} \times \frac{\left|P_{j} \mathrm{I} Q_{i}\right|}{|U|}=\sum_{j=1}^{m} \frac{\left|P_{j} \mathrm{I} Q_{s}\right|}{\left|Q_{s}\right|} \times \frac{\left|P_{j} \mathrm{I} Q_{s}\right|}{|U|}+\sum_{i \neq s} \sum_{j=1}^{m} \frac{\left|P_{j} \mathrm{I} Q_{i}\right|}{\left|Q_{i}\right|} \times \frac{\left|P_{j} \mathrm{I} Q_{i}\right|}{|U|}$ $<\frac{\left|Q_{s}\right|}{|U|}+\sum_{i \neq s} \frac{\left|Q_{i}\right|}{|U|}<\sum_{i=1}^{n} \frac{\left|Q_{i}\right|}{|U|}=1$.

According to Lemma3 and Definition 3 we can easily get the following theorem:

[Theorem 2] $\sigma_{A}=1 \Leftrightarrow \mathrm{U} / \mathrm{A}$ is a partition subdivision of $\mathrm{R}_{\mathrm{C}}$. 
Now we come to the significance of consistent degree $\sigma_{A}$ : $\mathrm{Rc}=\left\{\underline{\mathrm{C}} \mathrm{Y}_{0}, \underline{\mathrm{C}} \mathrm{Y}_{1}, \underline{\mathrm{CY}} \mathrm{Y}_{2}, \ldots, \underline{\mathrm{C}} \mathrm{Y}_{\mathrm{m}}\right\}$ not only divide the consistent objects belong to different decision class $\mathrm{Y}_{1}, \mathrm{Y}_{2}, \ldots, \mathrm{Y}_{\mathrm{m}}$ into different partition blocks $\underline{\mathrm{C}} \mathrm{Y}_{1}, \underline{\mathrm{C}} \mathrm{Y}_{2}, \ldots, \underline{\mathrm{C}} \mathrm{Y}_{\mathrm{m}}$, but also put all the inconsistent objects in one partition block $\underline{\mathrm{C}} \mathrm{Y}_{0}$. Therefore, when U/A is not a partition subdivision of $\mathrm{R}_{\mathrm{C}}$, it is positive that the consistent objects belong to different decision class are mixed in one partition block, or the consistent objects and the inconsistent objects are mixed in one partition block. From the proof of Theorem 2 we can see that the more of these mixtures, the smaller of $\sigma_{A}$, and the less importance of A for decision attribute.

\section{A Heuristic Knowledge Reduction Algorithm Based on Partition Subdivision and Consistent Degree}

Searching for all reduction or minimal reduction of a decision table was already proved to be a NP-hard problem ${ }^{[6,7]}$; therefore, making use of some heuristic information to reduce the searching space is the main idea in most of the algorithms, which can get a minimal reduction or a suboptimal reduction. An algorithm is designed in this paper as follows: Taking the consistent degree of every condition attribute with respect to $R_{C}$ as the heuristic information, the condition attribute set is presented in the consistent degree's descending order, then we begin to search from the first attribute of this set until the searching result is a partition subdivision of $R_{C}$, which is the minimal reduction.

[Algorithm 1] Input: decision table $T=(U, C, D)$

Output: a minimal reduction of $\mathrm{T}$

Initialize REDU $=\varnothing$.

(1) Compute U/C, U/D, $\mathrm{R}_{\mathrm{C}}$;

(2) for each $\mathrm{Ci} \in \mathrm{C}$, compute $\mathrm{U} / \mathrm{Ci}$, if $\mathrm{U} / \mathrm{Ci}$ is a partition subdivision of $\mathrm{R}_{\mathrm{C}}$, then $\mathrm{REDU}=\{\mathrm{Ci}\}$ and go to (8);

If every $\mathrm{U} / \mathrm{Ci}$ is not the partition subdivision $\mathrm{R}_{\mathrm{C}}$, then go to (3);

(3) for each $\mathrm{Ci} \in \mathrm{C}$, calculate the consistent degree $\sigma_{C_{i}}$, and $\mathrm{C}$ is presented in the consistent degree's descending order as $\mathrm{C}=\{\mathrm{A} 1, \mathrm{~A} 2, \ldots, \mathrm{An}\}$;

(4) $R E D U=\{A 1, A 2\}, i=2$; If $U / R E D U$ is a partition subdivision of $R_{C}$, then go to (8). Else, go to (5);

(5) $\mathrm{i}=\mathrm{i}+1, \mathrm{REDU}=\mathrm{REDU} \cup\{\mathrm{Ai}\}$;

(6)If $\mathrm{U} / \mathrm{REDU}$ is a partition subdivision of $\mathrm{R}_{\mathrm{C}}$, then go to (7). Else, go to (5);

(7) for $(\mathrm{k}=\mathrm{i}-1 ; \mathrm{k}>=1 ; \mathrm{k}--)$

If $\mathrm{U} /(\operatorname{REDU}-\{\mathrm{Ak}\})$ is a partition subdivision of $\mathrm{R}_{\mathrm{C}}$, then $\mathrm{REDU}=$ REDU- $\{\mathrm{Ak}\}$ and go to (8)。

(8) Output REDU。 
Supplementary explanation: Compute U/C, U/D, U/Ci and U/REDU by Algorithm 1 in reference [10];Compute $\operatorname{POS}_{C}(\mathrm{D})$ by Algorithm 2 in reference[11], so $\mathrm{R}_{\mathrm{C}}$ is obtained simultaneously.

We analyze the time complexity of Algorithm 1 as follows: The time complexity of (1) is $\mathrm{O}(|\mathrm{C}||\mathrm{U}|)^{[10,11]}$. In the worst circumstance, the whole $\mathrm{C}$ is minimal reduction, then the time complexity of (2) is $\mathrm{O}\left(|\mathrm{C}|^{2}|\mathrm{U}|\right)$, (3) is $\mathrm{O}\left(|\mathrm{C}|^{2}|\mathrm{U}|\right)$, (4) (5) (6) is $\mathrm{O}\left(|\mathrm{C}|^{2}|\mathrm{U}|\right)$, (7) is $\mathrm{O}\left(|\mathrm{C}|^{2}|\mathrm{U}|\right)$. Therefore, the time complexity of Algorithm 1 is $\mathrm{O}\left(|\mathrm{C}|^{2}|\mathrm{U}|\right)$, which is lower than the time complexity $\mathrm{O}\left(|\mathrm{C}|^{2}|\mathrm{U}||\log | \mathrm{U}||\right)$ of Algorithm 2 in reference[1].

The advantage of Algorithm 1:

1) There is no computation for $\operatorname{CORE}_{D}(\mathrm{C})$.

2) Judging if REDU is a subdivision of $R_{C}$ instead of judging if $\operatorname{POS}_{\text {REDU }}(\mathrm{D})=\operatorname{POS}_{\mathrm{C}}(\mathrm{D})$, the calculation amount shrink evidently.

3) Even in the worst circumstance we only calculate the importance of each single condition attribute for decision attribute, so the calculation amount is less than calculating the importance of some attributes' combination. The calculation of consistent degree is easier than the calculation of condition information entropy too.

Now we clarify Algorithm 1 by the following example ${ }^{[1]}$ :

Table 5. Decision Table 4.

\begin{tabular}{lllllll}
\hline $\mathrm{U}$ & $\mathrm{a}$ & $\mathrm{b}$ & $\mathrm{c}$ & $\mathrm{e}$ & $\mathrm{f}$ & $\mathrm{d}$ \\
1 & 0 & 0 & 0 & 0 & 1 & 0 \\
2 & 0 & 1 & 1 & 1 & 0 & 1 \\
3 & 1 & 1 & 0 & 1 & 1 & 1 \\
4 & 0 & 1 & 1 & 1 & 0 & 0 \\
5 & 0 & 0 & 1 & 0 & 1 & 0 \\
6 & 1 & 1 & 0 & 1 & 0 & 1 \\
7 & 0 & 1 & 1 & 1 & 1 & 1 \\
8 & 1 & 1 & 1 & 0 & 1 & 1 \\
9 & 1 & 1 & 0 & 1 & 1 & 0 \\
10 & 0 & 1 & 1 & 1 & 1 & 0 \\
\hline
\end{tabular}

(1) $\mathrm{U} / \mathrm{D}=\{\{1,4,5,9,10\},\{2,3,6,7,8\}\}, \mathrm{U} / \mathrm{C}=\{\{1\},\{2,4\},\{3,9\},\{5\},\{6\},\{7,10\},\{8\}\}$, $\mathrm{R}_{\mathrm{C}}=\{\{1,5\},\{6,8\},\{2,3,4,7,9,10\}\}$.

(2) $\mathrm{U} /\{\mathrm{a}\}=\{\{1,2,4,5,7,10\},\{3,6,8,9\}\}, \mathrm{U} /\{\mathrm{b}\}=\{\{1,5\},\{2,3,4,6,7,8,9,10\}\}$, $\mathrm{U} /\{\mathrm{c}\}=\{\{1,3,6,9\},\{2,4,5,7,8,10\}\}, \mathrm{U} /\{\mathrm{e}\}=\{\{1,5,8\},\{2,3,4,6,7,9,10\}\}$, $\mathrm{U} /\{\mathrm{f}\}=\{\{2,4,6\},\{1,3,5,7,8,9,10\}\}$.

None of them is the partition subdivision of $\mathrm{R}_{\mathrm{C}}$.

(3) $\sigma_{\{a\}}=0.533, \sigma_{\{b\}}=0.7, \sigma_{\{c\}}=0.4, \sigma_{\{e\}}=0.695, \sigma_{\{f\}}=0.467$, then C is presented in the consistent degree's descending order as $C=\{b, e, a, f, c\}$.

(4) (5) $6 \mathrm{U} /\{\mathrm{b}, \mathrm{e}\}, \mathrm{U} /\{\mathrm{b}, \mathrm{e}, \mathrm{a}\}$ are not the partition subdivision of $\mathrm{R}_{\mathrm{C}}, \mathrm{U} /\{\mathrm{b}, \mathrm{e}, \mathrm{a}, \mathrm{f}\}$ is the partition subdivision of $R_{C}$, so $R E D U=\{b, e, a, f\}$. 
(7) $\mathrm{U} /\{\mathrm{b}, \mathrm{e}, \mathrm{f}\}, \mathrm{U} /\{\mathrm{b}, \mathrm{a}, \mathrm{f}\}$ are not the partition subdivision of $\mathrm{R}_{\mathrm{C}}, \mathrm{U} /\{\mathrm{e}, \mathrm{a}, \mathrm{f}\}$ is the partition subdivision of $R_{C}$, so $R E D U=\{e, a, f\}$.

(8) Output $\operatorname{REDU}=\{\mathrm{e}, \mathrm{a}, \mathrm{f}\}$.

\section{Experimental Results}

We choose Decision table 4 in this paper and some decision tables in UCI machine learning database, and implemented Algorithm 1 in this paper and Algorithm 2 in reference[1] by Java language on our PC(Intel(R) Core(TM)2 2.33GHz, 1.96GB RAM,WINXP). The experimental results are as follows:

Table 6. Experimental Results Table.

\begin{tabular}{|c|c|c|c|c|c|c|c|c|}
\hline \multirow[t]{2}{*}{ Decision table } & \multirow{2}{*}{$\begin{array}{l}\text { If it is a } \\
\text { consistent } \\
\text { decision } \\
\text { table }\end{array}$} & \multirow{2}{*}{$\begin{array}{l}\text { The } \\
\text { number } \\
\text { of in- } \\
\text { stances }\end{array}$} & \multirow{2}{*}{$\begin{array}{l}\text { The } \\
\text { number } \\
\text { of condi- } \\
\text { tion at- } \\
\text { tributes } \\
\text { before } \\
\text { reduction }\end{array}$} & \multirow{2}{*}{$\begin{array}{l}\text { The } \\
\text { number } \\
\text { of condi- } \\
\text { tion at- } \\
\text { tributes } \\
\quad \text { in } \\
\text { the } \\
\text { minimal } \\
\text { reduction }\end{array}$} & \multicolumn{2}{|c|}{$\begin{array}{l}\text { Algorithm 1in this pa- } \\
\text { per }\end{array}$} & \multicolumn{2}{|c|}{$\begin{array}{l}\text { Algorithm } 2 \text { in refer- } \\
\text { ence[1] }\end{array}$} \\
\hline & & & & & $\begin{array}{l}\text { The } \\
\text { number } \\
\text { of con- } \\
\text { dition } \\
\text { attrib- } \\
\text { utes af- } \\
\text { ter re- } \\
\text { duction }\end{array}$ & $\begin{array}{l}\text { Execution } \\
\text { time } / \mathrm{s}\end{array}$ & $\begin{array}{l}\text { The num- } \\
\text { ber of } \\
\text { condition } \\
\text { attributes } \\
\text { after re- } \\
\text { duction }\end{array}$ & $\begin{array}{l}\text { Execution } \\
\text { Time } / \mathrm{s}\end{array}$ \\
\hline Table 5 & No & 10 & 5 & 3 & 3 & 0.01 & 3 & 0.02 \\
\hline Voting-records & Yes & 435 & 16 & 9 & 9 & 0.12 & 9 & 0.15 \\
\hline Tic-tac-toe & Yes & 958 & 9 & 8 & 8 & 0.32 & 8 & 0.38 \\
\hline zoo & No & 101 & 17 & 10 & 11 & 0.06 & 10 & 0.07 \\
\hline mushroom & Yes & 8124 & 22 & 4 & 4 & 3.23 & 4 & 3.80 \\
\hline chess end-game & Yes & 3196 & 36 & 29 & 29 & 2.73 & 29 & 3.09 \\
\hline
\end{tabular}

From Table 6. we can see that the execution time of Algorithm 1 in this paper is less than that of Algorithm 2 in reference[1].

\section{Conclusions}

Being illuminated by the set cluster $\mathrm{R}_{\mathrm{C}}{ }^{[1]}$ and the decision power ${ }^{[3]}$, this paper has found and proved the following laws by Theorem 1 and Theorem 2 : In decision table $\mathrm{T}=(\mathrm{U}, \mathrm{C}, \mathrm{D}), \mathrm{A} \subseteq \mathrm{C}, \mathrm{POS}_{\mathrm{A}}(\mathrm{D})=\mathrm{POS}_{\mathrm{C}}(\mathrm{D}) \Leftrightarrow \mathrm{U} / \mathrm{A}$ is a partition subdivision of $\mathrm{R}_{\mathrm{C}} \Leftrightarrow \sigma_{A}=1$ ( $\sigma_{A}$ is the consistent degree of $\mathrm{A}$ with respect to $\left.\mathrm{R}_{\mathrm{C}}\right)$.

Consequently, a heuristic knowledge reduction algorithm, Algorithm 1, is designed. Making use of Theorem 1, this algorithm judges if REDU is a subdivision 
of $\mathrm{R}_{\mathrm{C}}$ instead of judging if $\operatorname{POS}_{\mathrm{REDU}}(\mathrm{D})=\mathrm{POS}_{\mathrm{C}}(\mathrm{D})$, so the calculation amount shrink evidently. From the proof of Theorem 2 we can see that the smaller of $\sigma_{A}$, the less importance of $\mathrm{A}$ for decision attribute, so it is rational that this algorithm takes the consistent degree $\sigma_{A}$ as the heuristic information to reduce the searching space. And the calculation of consistent degree is easier than the calculation of condition information entropy. The time complexity of this algorithm is lower too.

Finally, The results of experiment show that this algorithm is more efficient than Algorithm 2 in reference[1] actually.

\section{References}

1. LIU Qi-he, LI Fan, MIN Fan, YE Mao, and YANG Guo-wei,"An Efficient Knowledge Reduction Algorithm Based on New Conditional Information Entropy", Vol.20, No.8, pp.878882, Control and Decision, 2005.

2. JIANG Si-yu and LU Yan-sheng,"Two New Reduction Definitions of Decision Table", Vol.27, No.3, pp.512-515, Mini- Micro Systems, 2006.

3. XU Zhang-yan, SONG Wei, YANG Bing-ru, GAO Jing and HOU Wei,"Note on 'Two New Reduction Definition of Decision Table'”, Vol.28 ,No.9, pp.1686-1689,Journal of Chinese Computer Systems, 2007.

4. WANG Guo-yin: Rough Set Theory and Knowledge Acquisition, Xi'an Jiaotong University Publishing Company, Xi'an2001.

5. LIU Qing: Rough sets and Rough Reasoning, Science Publishing Company, Beijing 2001

6. Hu X.H. and Nick C. "Learning in relational databases: A rough set approach", Vol.11, No.2, pp.323-338,International Journal of Computational Intelligence, 1995

7. XU Zhang-yan, LIU Zuo-peng, YANG Bing-ru and SONG Wei,"A Quick Attribute Reduction Algorithm with Complexity of $\max \left(\mathrm{O}(|\mathrm{C}||\mathrm{U}|), \mathrm{O}\left(|\mathrm{C}|^{2}|\mathrm{U} / \mathrm{C}|\right)\right)$ ), Vol.20, No.3, pp.391399, Chinese Journal of Computers, 2006.

8. Pawlak Z, "Rough sets", Vol.11, No.5, pp.341-356, International Journal of Computer and Information Science, 1982.

9. Pawlak Z: Rough Sets: Theoretical Aspects of Reasoning about Data, Kluwer Academic Publishers, Dordrecht,1991

10. Pawlak Z, Slowinski R, "Rough set approach to multi-attribute decision analysis", Vol.72, No.1, pp.443-459, European Journal of Operational Research, 1994. 